\title{
Educação especial e educação do campo: narrativa que desvela possibilidades e interfaces
}

\author{
Special education and field education: narrative \\ discovering possibilities and interfaces
}

Denise Meyrelles de Jesus ${ }^{1}$

Alexandro Braga Vieira²

Christiano Felix dos Anjos ${ }^{3}$

\section{Resumo}

A interface entre a educação especial e educação do campo tem sido pouco vislumbrada em pesquisas acadêmicas. A interface, as relações entre essas duas modalidades de ensino, se constitui em uma lacuna que poucos trabalhos se debruçam em desvelar. Nesse artigo, buscamos visibilizar a interface entre a educação especial e educação a partir das narrativas de uma pesquisadora que problematizou em sua dissertação a educação do campo. Como referencial teórico metodológico, nos apropriamos da natureza metodologia da cartografia simbólica de Boaventura de Sousa Santos onde buscamos a partir das narrativas da pesquisadora (des)territorializar, e (re)territorializar, mapas simbólicos da educação especial e da educação do campo para que ambas modalidades se percebam entre si. Como resultados, percebemos a presença da interface entre a educação especial e educação do campo no momento da atuação profissional dentro do município da autora pesquisada. Assim chamamos a atenção que a interface se encontra presente nos vários espaços onde a modalidade da educação do campo é efetivada, apenas ainda não foi visibilizada ainda, tanto por seus profissionais no chão da escola quanto para aqueles que produzem conhecimento sobre essas duas modalidades.

\footnotetext{
${ }^{1}$ Professora do Centro de Educação e do Programa de Pós-Graduação em Educação da Universidade Federal do Espírito Santo. Graduação em Pedagogia pela Ufes. Mestrado em Educação pela University of Iowa. Doutorado em Psicologia da Educação pela University of California. Pós-doutorado em Educação pela Universidade de São Paulo. E-mail: jesusdenise@hotmail.com.

2 Professor do Centro de Educação e Coordenador do Programa de Pós-Graduação de Mestrado Profisisonal em Educação da Universidade Federal do Espírito Santo. Professor do Programa de Pós Graduação de Ensino, Educação Básica e Formação de Professores da Ufes / Alegre-ES. Graduação em Letras e pEdagogia. Mestrado, doutorado e pós-doutorado em Educação pela Ufes. E-mail: allexbraga@hotmail.com.

3 Possui graduação em Pedagogia, mestrado e doutorando em Educação pela Universidade Federal do Espírito Santo. E-mail: avitima@gmail.com.
} 
Palavra Chave: Educação Especial. Educação do Campo. Interface.

\section{Abstract}

The interface between special education and field education has been little glimpsed in academic research. Thinking about its interface is a gap that few studies have focused on revealing the relations between these two modes of teaching. From this in our article, we seek to visualize the interface between special education and education based on the narratives of a researcher who problematized the field education in her dissertation. As a theoretical and methodological reference, we take the methodology of the symbolic cartography of Boaventura de Sousa Santos, where we seek from the narratives of the researcher (des) to territorialize, and (re) territorialize, symbolic maps of special education and field education so that both modalities to perceive each other. As results, we perceive the presence of the interface between the special education and the education of the field at the moment of the professional performance within the community of the researched author. Thus we draw attention to the fact that the interface is present in the various spaces where the field education modality is implemented, but it has not yet been seen either by its professionals on the school floor or by those who produce knowledge about these two modalities.

Keyword: Special Education. Field Education. Interface.

\section{Para iniciar a conversa}

Visibilizar movimentos de interfaces e possibilidades que nelas existem entre as áreas de educação especial e educação do campo, tem se constituído um grande desafio. Tal afirmação se dá principalmente por conta do status de invisibilização, que ainda persiste dentro da realidade educacional brasileira, acabando por produzir cada vez mais desigualdade e exclusão nas duas modalidades de ensino e entre elas. Tal movimento de produção de desigualdade e exclusão acaba se tornando bilateral, quando a educação especial e educação do campo, não se percebem produzindo hierarquias 
dentro de sua realidade silenciando o aluno público alvo da educação especial nas escolas do campo (ANJOS, 2016).

Assim sendo vamos percebendo que os alunos dessas duas modalidades em interface vão sendo estigmatizados e marginalizados dentro de um sistema de educação que supostamente deveria se constituir em uma garantia para a sua escolarização, mas tem se configurado no Brasil em uma condição "tímida, descentrada e ambivalente" (NOZU, 2017).

Concordamos com Caiado (2010) quando nos permite refletir sobre o que ela chamou de uma "dupla exclusão", as duas modalidades se encontram em processo de fragilidade dentro da realidade educacional brasileira. Quando levamos em conta a interface entre a educação especial e educação do campo e chamamos a atenção para a precarização da escolarização de seus alunos, estamos possibilitando o direito à educação. Dizemos de processos de escolarização, a partir da realidade que os constituem, pensando a realidade em que vivem em diálogo com as representações sociais e de escolarização que se encontram presentes em seus territórios.

Reflexo disso se torna aparente quando tomamos um levantamento do quantitativo de escolas do campo em território nacional e de seus alunos matriculados. Os números levantados obtidos a partir do sítio Qedu ${ }^{4}$ que compila números oficiais do censo educacional cuja última atualização é do ano de 2015. Seguindo esse caminho, o banco de dados nos apresenta quantitativo 79.341 escolas do campo no ano de 2010, por sua vez, no ano de 2015 temos uma diminuição de 14,87\% das escolas situadas em regiões rurais, isso significa o fechamento de 11.800 escolas nesses cinco anos.

Quando comparamos esses dados de fechamento de escolas do campo juntamente com o número de matrículas nas áreas rurais a partir de um levantamento do censo escolar (ANJOS, 2017) e tendo como foco os alunos público alvo da Educação Especial que estudam no campo, temos o aumento ducation_stage $=0 \&$ item $=$ matrículas $>$ 
de $27,60 \%$ no mesmo periodo evidenciado anteriormente. Assim, percebemos delineamentos de uma politica de sucateamento das escolas do campo e de precarização da formação desses sujeitos que possuem por direito serem escolarizados próximo de onde moram.

Acompanhado dessa discussão, também percebemos uma invisibilização acadêmica sobre a interface entre a educação especial e educação do campo, Caiado (2010), Jesus, Anjos e Bergami (2011), Anjos (2016), Nozu (2017) nos mostram a pouca produção existente sobre a temática e enfatizam a necessidade de maior aprofundamento.

A partir desses autores significamos a importância visibilizar interfaces existentes que são produzidas como invisíveis, (SANTOS, 2010).

Percebidas as necessidades de visibilização desses alunos público alvo da educação especial ${ }^{5}$ em sua interface com as escolas do campo, consideramos a importância do movimento de dar continuidade e aprofundamento à interface da educação especial com a educação do campo. Neste caso, vale ressaltar que este texto se dá a partir dos dados levantados durante nossa pesquisa de mestrado (2014-2016), que tinha como foco, mais especificamente, nos aproximarmos das pesquisas acadêmicas no âmbito do Programa de Pós-Graduação em Educação da Universidade Federal do Espírito Santo. Mediante a análise dos trabalhos produzidos (dissertações e teses).

Entretanto, temos em nossa percepção que o texto acadêmico ele se constitui em muito mais que um relatório de pesquisa, ele é uma narrativa que perpassa o "ser pesquisador", o "ser profissional da educação" e o "ser pessoal" que move o pesquisador em ir ao encontro de suas inquietações movidas pela sua história de vida e profissional. Nesse sentido, buscamos mais que analisar as produções acadêmicas, fomos ao encontro dos seus autores, que nos permitiram ampliar a dimensão da pesquisa, que superou o texto acadêmico e a centralidade discursiva presente nas suas dissertações e teses.

\footnotetext{
${ }^{5}$ Entendemos o público-alvo da educação especial os alunos com deficiência, transtornos globais do desenvolvi-me e altas habilidades e super dotação que se encontra de acordo coma Política Nacional de Educação Especial na Perspectiva da Educação Inclusiva do ano de 2008.
} 
No momento da pesquisa de mestrado, fizemos a leitura de aproximadamente 30 textos acadêmicos entre dissertações e teses e elegemos 11 autores para análise aprofundada de suas produções e posterior encontro com eles em uma entrevista semiestruturada, Nosso objetivo sendo visibilizar de pistas que pudessem nos apontar para: a invisibilização da interface entre a educação especial e educação do campo, pistas de sua existência ou no vislumbre da interface se materializando em um dado contexto, das realidades pesquisadas por esses autores.

Assim sendo, para a produção deste artigo, investiremos os esforços em uma única produção/narrativa e temos como objetivo compreender quais os movimentos e possibilidades de interface entre a educação especial e educação do campo, como ela vem sendo construídas, a partir de uma pesquisadora que produziu conhecimento sobre a realidade do campo no município de Domingos Martins do estado do Espírito Santo e que se encontra presente atuando, nesse mesmo municipio, como uma das profissionais que atua na gestão educacional.

Para tal envolvimento lançamos mão das teorizações da Boaventura de Sousa Santos e de seu olhar teórico metodológico da cartografia simbólica (2007), juntamente com outros autores que nos possibilitaram focar as lentes em movimentos de (des)territorializar e (re)territorializar mapas sociais construídos por nossa pesquisadora/narradora com o intuito de fazer emergir a interface dentro de sua realidade de pesquisa.

\section{Boaventura de Sousa Santos e o caminho teórico metodológico}

Consideramos importante a teoria de Boaventura de Sousa Santos (2006), pois ela nos fornece uma grande contribuição para o nosso viés de pesquisa, que possui como objetivo central a desconstrução das hierarquias, a produção de diálogos e a visibilização da interface entre a educação especial e a educação do campo.

Em Santos (2006), podemos encontrar o material que torna possível a percepção dos movimentos de "silêncio" e produção da "não-existência" do 
sujeito público-alvo da educação especial nas escolas do campo. Do mesmo modo, o autor colabora com nossas reflexões a respeito da educação do campo na educação especial. Não partimos do pressuposto de que esses sujeitos são excluídos propositadamente das produções acadêmicas na interface entre a educação do campo e educação especial. A forma de produção científica é que se torna tão centrada em uma única percepção da realidade, que acaba não dialogando com outras realidades e práticas sociais.

A partir das lentes de Santos (2007, p. 20), também não há necessidade de uma nova área de conhecimento para se fazer pensar a interface, e sim um novo/outro olhar, para tornar crediveis essas existências invisiveis. "Não é simplesmente de um conhecimento novo que necessitamos; o que necessitamos é de um novo modo de produção de conhecimento. Não necessitamos de alternativas, necessitamos é de um pensamento alternativo as alternativas".

Santos (2010) permite refletir sobre o pensamento científico moderno e ocidental e o entende como um pensamento abissal. $O$ autor assume que existem linhas que dividem a realidade social, "deste lado da linha" e "do outro lado da linha". Esse "outro lado da linha" é uma produção de inexistência. Ele não é relevante para o "deste lado da linha", não é compreensivel.

$\mathrm{Na}$ introdução deste trabalho, quando falamos em silêncio e invisibilidade nas produções acadêmicas, compreendemos que temos essa percepção de que existe uma linha abissal entre as duas áreas de conhecimento estudadas. Não que uma esteja "deste lado da linha" e outra do "outro lado da linha", mas ambas estão tanto de um lado quanto do outro da linha.

Assim colocado, entendemos que a perspectiva metodológica cartográfica que Santos nos apresenta, fez ser possivel decompor camadas hierárquicas que invisibilizam (SANTOS, 2007) e provocam desigualdade e exclusão. O direcionamento de nossa perspectiva de pesquisa é exatamente buscar luz nesses sujeitos invisibilizados.

Isso nos fez colocar em movimento e nos permitiu “[...] operar essa inversão, ou essa fase de inversão, [...] significa ainda operar no terreno e no interior do sistema desconstruído" (DERRIDA 2001, apud SKLIAR, 2010, p. 
3). Assim, procuramos decompor os discursos, revelando seus pressupostos, suas ambiguidades, suas contradições.

Boaventura de Souza Santos (1988) e também o autor Jörn Seemann (2010) nos ajudam a pensar a proposta de Santos, aproximando a cartografia à área de Educação. Isso nos permite elaborar uma projeção daquilo que for mapeado como uma forma de representação da realidade, compreendendo aqui a realidade sempre em transformação e ressignificação efetivada por nós. Assim, nessa representação, temos dois mapas simbólicos, o da educação do campo e o da educação especial que se entrecruzam e se invisibilizam.

Quando nos propomos pensar como vem se dando a interface entre duas modalidades, estamos nos colocando como tarefa identificar as singularidades de cada grupo, seus territórios e reconhecer, a partir do vislumbre em grande escala (SANTOS, 1988), que esses grupos fazem parte de um mesmo território. Assim, iremos territorializar, (des)territorializar e (re)territorializar, propondo sempre desestabilizar formas hegemônicas de compreensão de território.

Compreendemos, como Seemann (2010, p. 30), que os mapas se constituem em um aparato metafórico, “[...] fazem parte da comunicação humana que permite uma ligação e o estabelecimento de relações entre campos diferentes e a incursão em terrenos novos e desconhecidos".

Por esse viés, fomos entendendo que a produção acadêmica sobre a educação especial e educação do campo do PPGE/UFES é uma sucessiva construção de mapas simbólicos que evidenciam as duas modalidades de ensino, suas produções e significações dentro de cada modalidade produz linhas que acabam por separar seus territórios, impedindo que haja uma tradução (SANTOS, 2006) entre os saberes e fazeres de cada área e se efetive a interface.

Para melhor delinear nossos movimentos que consistiram no processo metodológico já sinalizado na introdução desse trabalho, é importante apresentar que nossa pesquisa se deu em 2 momentos. 
- Primeiro momento levantamento análise da produção acadêmica de dissertações e teses sobre a educação do Campo e a educação Especial nos anos de 2006 a 2014, no âmbito do PPGE/UFES;

- Análise das narrativas dos autores das dissertações e teses levantadas.

Nosso foco era entender os silenciamentos e pistas que pudessem emergir dentro das dissertações e teses produzidas no PPGE/UFES, no que diz respeito à interface entre a educação especial e educação do campo. Assim, nos debruçamos em olhar os trabalhos que envolviam cada temática tanto a Educação Especial quanto a Educação do Campo. Sabíamos que dentro do arco temporal que elegemos apenas um estudo havia se debruçado, especificamente, sobre a interface entre essas duas áreas. Esse foi, então, um ponto disparador em compreender que outras pistas poderiam surgir ou que mecanismos eram reproduzidos que pudessem manter o silenciamento entre essas duas áreas.

A escolha por esse período se justifica a partir do ano que começou a se depositar online via sítio do próprio PPGE/UFES dissertações e teses e o ano de 2014 foi o ano de corte para o levantamento pois foi o ano de realização de nossa pesquisa.

Elegemos dissertações e teses para análise que buscavam pesquisar regiões fora da região metropolitana de Grande Vitória, assim as pesquisas poderiam ter uma aproximação maior com o ambiente do campo pois são do interior do Espírito Santo e com isso possuem uma realidade do campo que compõe suas realidades.

Com o início das leituras, fomos percebendo que o conhecimento sistematizado acadêmico (as teses e dissertações) não se distancia do próprio sujeito que pesquisa, de suas subjetividades, conflitos, tensões e dúvidas, pois, uma implicação para o "ser pesquisador" é que ele não é um ser desencarnado e totalmente neutro. "A ciência tem sempre a marca de seu construtor, que nela não é só tratada a realidade, mas igualmente ele a molda do seu ponto de vista” (DEMO, 1997, p. 33) 
Com isso, passamos a entender que as dissertações e teses dos autores a serem estudadas se constituem em narrativas que permitem compreender, a partir de Cunha (1997, s. p.):

\begin{abstract}
Quando uma pessoa relata os fatos vividos por ela mesma, percebe-se que reconstrói a trajetória percorrida dando-lhe novos significados. Assim, a narrativa não é a verdade literal dos fatos mas antes é a representação que deles faz o sujeito e, dessa forma, pode ser transformadora da própria realidade.
\end{abstract}

Por sua vez, em um aprofundamento do que consiste o entendimento sobre narrativa, faz-se importante chamar a atenção para o que Rabelo (2011, p. 171) nos apresenta

A narrativa nos permite compreender a complexidade das estórias contadas pelos individuos sobre os conflitos e dilemas de suas vidas. Bolivar (2002) entende como a qualidade estruturada da experiência percebida é vista como um relato, captando a riqueza e os detalhes dos significados nos assuntos humanos, tendo como base as evidências do mundo da vida. Reconstrói-se a experiência refletindo sobre o vivido e dando significado ao sucedido.

Para além de passarmos a enxergar as teses e dissertações como narrativas, percebemos outras implicações que foram postas a inspirados em Guimarães (2014) e seu olhar a partir de Heidegger, entendemos que o autor e sua pesquisa não se encontra descolado de suas dimensões pessoais, profissionais dentro do seu "ser" pesquisador. O que move o pesquisador está ligado as dimensões do "ser pesquisados", "ser profissional da educação" e o seu "ser pessoal", é um tripé que constitui o autor e sua pesquisa.

Para sistematizar as leituras e fazer conseguir abstrair as pistas e silenciamentos sobre a Interface entre a educação especial e educação do campo nos relatórios de pesquisa, outros dois autores nos ajudaram a pensar esse fazer, a primeira consistiu em Almeida (2010) que também analisou produções acadêmicas e se utilizou de um quadro esquemático que decompunha o texto em diversos tópicos para melhor organizar os objetivos de leitura e não perder pistas que pudessem se perder quando o texto é olhado de forma uniforme. Juntamos o quadro esquemático utilizado por essa autora com de Willian Labov (1972) que nos trouxe elementos que nos ajudou a compreender os tópicos existentes em uma narrativa. Ele então nos aponta 
elementos que a narrativa deve apresentar e que, por sua vez, possuem uma função. Uma narrativa completa deve ter seis elementos: o resumo, que é o sumário da substância da narrativa; a orientação, consiste no tempo, lugar, situação, participantes; complicação da ação, sequência de acontecimentos; avaliação, que nos direciona ao significado e sentido da ação, atitude do narrador; resolução, aquilo que aconteceu, como foi resolvida a complicação e o Coda, o elemento que termina a narrativa voltando para o presente. Nesse sentido, o narrador/autor da produção estará colocando sua experiência, avaliando e interpretando-a.

Assim nossa ficha de análise das dissertações e teses que também eram percebidas como narrativas por nós ficou desta forma como apresentado no quadro 1

\section{1 - Ficha de organização de sintese das narrativas escritas (dissertações e teses)}

\begin{tabular}{|l|}
\hline $\mathbf{1}$ - Resumo - Resumo da dissertação ou tese \\
\hline $\mathbf{2}$ - Orientação \\
\hline Título do da Dissertação ou Tese \\
\hline Nome do Autor \\
\hline Ano de Defesa \\
\hline Linha de Pesquisa \\
\hline A - Introdução \\
\hline B - Justificativa \\
\hline C - Objetivos \\
\hline E - Referencial teórico \\
\hline
\end{tabular}




\section{3 - Complicação}

A - Apresentação/ análise dos dados

\section{4 - Avaliação/ 5 - Resolução/ 6 - Coda}

A - Conclusão

Fonte: Elaborado pelo autor.

Com essa ficha de organização, também desenvolvemos uma segunda ficha (quadro 2) em que nossas impressões sobre o entendimento do autor sobre a Educação Especial e a Educação do Campo eram colocadas. Essa segunda ficha de organização se desenhou em forma de perguntas que fazíamos para os autores, à medida que íamos avançando na leitura. As perguntas foram diferentes, considerando se o autor pesquisou sobre Educação Especial ou Educação do Campo.

\section{2 - Perguntas direcionadas ao texto}

\begin{tabular}{|l|l|}
\hline $\begin{array}{l}\text { Autor que pesquisou sobre } \\
\text { Educação Especial }\end{array}$ & $\begin{array}{l}\text { Autor que pesquisou sobre Educação do } \\
\text { Campo }\end{array}$ \\
\hline $\begin{array}{l}\text { O que é Educação Especial e o } \\
\text { que é ser aluno com } \\
\text { necessidades educacionais } \\
\text { especiais? }\end{array}$ & $\begin{array}{l}\text { O que é Educação do Campo e o que é ser } \\
\text { aluno do campo? }\end{array}$ \\
\hline Como o pesquisador se encontra implicado em sua área de estudo? \\
\hline $\begin{array}{l}\text { O que fala sobre a Educação do } \\
\text { Campo? }\end{array}$ \\
\hline
\end{tabular}


Fonte: Elaborado pelo autor.

Dentre todas as dissertações e teses analisadas elegemos 11 para o segundo momento de nossa pesquisa, que consistiu em ir até os autores em busca de formar uma segunda narrativa a partir que lhes fossem solicitados um novo/outro olhar para o sua própria dissertação e tese. Nosso objetivo era, com a análise de suas produções buscar que rememorassem as pistas que encontramos em seus textos nos levaram a entender que a interface entre a educação especial e educação do campo estivesse sendo silenciada. Acrescentamos em nosso encontro com os autores, utilizando de uma entrevista semiestruturada, elementos para esse diálogo que ampliasse a percepção do autor buscado rememorar no momento de sua pesquisa aquilo que foi suprimido de interface em sua pesquisa. Obviamente não estávamos dizendo que ele produzia os mecanismos que o silenciamento acontecia a partir da negação do autor para a interface, mas sim entendiamos que mecanismos de silenciamento eram potentes e nem mesmo o autor se atentava para elas.

Ao seu turno, em algumas narrativas, fizemos emergir na segunda narrativa elementos de interface que só não se encontravam em seus textos pois não faziam parte dos objetivos propostos por eles, mas que pela via de nossa pesquisa foi possivel visibilizar essas existências antes não percebidas (Santos, 2006).

Explicitando melhor nosso caminho metodológico, elegemos para esse artigo uma narrativa que consideramos que seja a que mais apresentou elementos que nos apresentou elementos de uma interface visibilizada na realidade que a autora estudou dentro do municipio de Domingos Martins.

Importante chamar a atenção que em nossa pesquisa via termo de consentimento livre e esclarecido e também documentado via gravações de vídeo, o nome dos autores são identificados, entendemos que para além da aceitação via o formulário citado, seus textos acadêmicos se encontram online e disponíveis para a leitura abertamente, suprimir o nome do autor não teria sentido para esse viés metodológico. 


\section{A interface entre a educação especial e educação do campo: territorializando, (des)territorializando (re)territorializando mapas simbólicos.}

Nos aproximamos da dissertação de Marciane Cosmo, que possui como título "Ser pomerana: histórias que desvelam as memórias, a experiência e os sentidos de ser professor" - Marciane Cosmo, pesquisa concluída no ano de 2014.

Nesta narrativa, vislumbramos a autora pesquisando sobre ser professor pomerano no município de Domingos Martins. Reflete que esse municipio recebeu muitos imigrantes pomeranos há mais de 150 anos e que a cultura é viva dentro dessa região até hoje.

A autora, em sua dissertação, problematiza sobre essa presença forte da cultura pomerana e sobre a politica de valorização e resgate cultural. Uma das principais politicas para tal é a oferta de diferentes línguas desses descendentes imigrantes nas comunidades. Justifica também que 19 das 50 escolas oferecem o ensino da lingua pomerana para seus alunos. Dessa forma, seu problema de pesquisa foi pensar como é ser professora pomerana no município de Domingos Martins.

Em sua metodologia, inspirou-se na fenomenologia para buscar a essência do que consiste ser pomerano, descrevendo as experiências vividas, os significados que a experiência tem para os sujeitos.

Em seu referencial teórico, adotou os fundamentos da psicologia fenomenológica e/ou existencial, apropriando-se das discussões de Forghieri. Também se aproximou dos estudos de Paulo Freire e seus conceitos de Ser Humano; Mundo; o Ser no Mundo; o Ser Inacabado; Subjetividade; Transcendência; Ser Mais; Existencialismo e Cultura. Buscou ainda (des)cobrir, (des)velar e (com)preender como esses conceitos estiveram presentes na vida do sujeito e que sentidos foram produzidos a partir deles ao narrar sua história de vida.

A autora encontra, na narrativa da professora pomerana, sua constituição do ser que problematiza a si mesma, inquietada e que intervém 
no mundo. Suas relações históricas construíram sua identidade e produziram movimentos de constante mudanças em que nada se encontra determinado. Sua existência carrega a concepção freiriana do inédito-viável (FREIRE, 2005) em sua pratica profissional e de vida. Assim sendo, ser pomerano fez ser possivel sentidos de emancipação, superar resistências e alcançar sonhos.

As pistas sobre a interface que nos instigaram a visitar Cosmo para compor esta segunda narrativa consistem na sua experiência na Secretaria de Educação do município e em suas aproximações com a educação especial, fazendo dois cursos de Especialização, Infância e Educação Inclusiva (2009) e Educação Especial e Inclusiva (2011).

Nesse retorno para a autora, percebemos de imediato uma aproximação muito grande, indicando como a interface entre a educação especial e a educação do campo poderia ser possível e vem sendo materializada no município de Domingos Martins.

Iniciando nosso encontro, a pesquisadora afirma sua identidade camponesa e pomerana. É filha de pais agricultores e estudou em escola do campo. Depois, como professora, lecionou na mesma escola em que estudou:

Então, eu sou filha de agricultores. Meus pais são do município de Marechal Floriano, e eu estudei em uma escola do campo, escola multisseriadas. Na verdade, era uma escola unidocente, tinha uma professora só. Estudei até a quarta série. Depois a escola cresceu o número de alunos e aí virou escola municipal de Ensino Fundamental. Terminando o Ensino Fundamental, eu fui fazer o Ensino Médio e fui fazer o curso profissionalizante de magistério. Fui para Venda Nova do Imigrante. E, em seguida, fui para a faculdade e fiz Pedagogia em uma faculdade aqui da região. Comecei a lecionar concomitantemente à faculdade. Eu já lecionava nessa escola onde eu estudei.

Como efetiva no município de Domingos Martins, começou a trabalhar na Secretaria de Educação, no Centro de Referência em Educação Inclusiva (Crei), tendo interesse pela temática no momento de sua entrada no mestrado. Mas a questão pomerana lhe chamou mais atenção, quando percebeu o quantitativo de alunos que iniciava sua escolarização e que o professor possuía enfrentamentos para lidar com esses alunos que tinham o pomerano como língua materna. Esse não saber da lingua dificultava o acesso do aluno à escola. 
Cosmo teve, durante sua pesquisa, uma aproximação com a educação especial ou pistas que pudessem nos direcionar para tal. Seu envolvimento com o Crei se dá antes de sua pesquisa, mas o momento da entrevista com essa autora se tornou frutifero, ao apresentarmos como o município de Domingos Martins trabalha a perspectiva da educação do campo.

O municipio hoje essencialmente trabalha com a perspectiva da educação do campo. Nós nos caracterizamos, trabalhamos com educação do campo. Noventa por cento de nossa economia é campesina. Das 49 escolas que nós temos no município só três se caracterizam urbanas, mas elas também trabalham com a perspectiva da educação do campo. Por quê? Mesmo estando sediadas... Por exemplo, aqui, em Domingos Martins, uma escola recebe alunos de várias adjacências que são crianças do campo. Então no censo. Para o censo, são urbanas, mas trabalham com a perspectiva da educação do campo (COSMO).

Essa é uma informação que nos permite entender que, pelo fato de todas as escolas do município serem consideradas na perspectiva da educação do campo o trabalho com o aluno público-alvo da educação especial nessas escolas se dá pelo olhar da realidade do campo, mas, ao mesmo tempo, também podemos inferir que a interface entre a educação do campo e educação especial nesse município é potencializada devido a essa realidade.

Em outras pesquisas que compuseram nosso estudo, os autores nos falam da dificuldade de trabalhar outras questões dentro da educação do campo, pois existem demandas que ainda precisam ser tratadas e que não permitem pensar ainda questões como a educação especial no âmbito do campo. Podemos trazer como exemplo, um município próximo de Domingos Martins, chamado Guarapari, nele temos uma outra configuração de suas escolas. Nesse município todas as escolas são consideradas como urbanas, mesmo tendo uma grande área rural em seu território, assim, todos os alunos, independentemente da região onde estejam matriculados, recebem uma educação que trata apenas do diálogo com a educação urbana.

Voltando ao município de Domingos Martins, quando ele assume essa relação com o campo, minimiza a desigualdade e a exclusão que a educação do campo sofre em outras regiões, abrindo espaço para outras demandas serem evidenciadas e trabalhadas. Por sua vez, diferente do município de Guarapari, esse admite também a sua característica histórica de ser 
essencialmente campesina, composta por seus imigrantes enraizados na constituição de seu próprio território.

Dessa forma a pesquisadora aponta para a necessidade que o município teve de atualizar sua perspectiva curricular e o trabalho que é pensado pela Secretaria que é discutido com os professores:

Nós nos sentimos incomodados porque educação do campo vem sendo trabalhada aqui, no município, desde 1999. E aí nós tínhamos um curriculo de 99 extremamente desatualizado. As demandas, os temas, as necessidades, quem discute, quem planeja, quem executa somos nós, como Secretaria de Educação, porque nós pensamos na perspectiva de fazer com, fazer com os professores, das necessidades que emergem deles. A Secretaria assumiu essa formação, mas sempre com interlocução com a universidade. De 2014, 2015, concluímos em dois mil e dezesseis, pensamos em elaborar o nosso currículo, reelaborar o nosso currículo a partir da perspectiva da educação do campo. Dentro do nosso currículo, ele já está sendo implementado em 2016, mas ele vai sair agora, em setembro (COSMO)

Chamando a atenção para a educação especial dentro desse currículo que se materializa neste ano de 2016, a pesquisadora enfatiza a construção desse documento que foi pensado articulando as demandas, experiências e como elas se encontram presentes dentro dos eixos que foram discutidos em conjunto entre Secretaria e professores:

Nós discutimos a questão da educação especial, da diversidade dentro do currículo, porque é inerente as nossas vivências, as nossas experiências, não dá para dissociar. E nós temos aqui, por exemplo hoje, todos esses eixos que estão descritos aqui, no sumário foram feitos por nós, Secretaria e professor. Nós discutimos item por item, eixo por eixo, formação por formação. Nós fazemos essa formação com os professores, para que o nosso currículo, seja a expressão de nossas práticas, traduza as nossas experiências. Adentrando um pouco mais sobre a questão do currículo nós discutimos a relação da Educação escolar no campo. Aî, na questão da diversidade, nós temos um capítulo que nós escrevemos e nós não escrevemos só com os professores de educação especial; nós escrevemos com todos os professores da rede. Então eu acho que a potência está em de se pensar o currículo, em se pensar essa coletividade, pensar o que todos estão pensando e como todos veem a diversidade, porque não é mais o sujeito daquela criança que fica lá na sala de recursos ou que fica com a auxiliar, ou que fica no contra turno, né? Nós pensamos a criança como sendo um sujeito parte integrante dessa inclusão (COSMO).

Essa fala da autora nos faz pensar os sentidos da potência de trabalhar em coletivo e dialogando as práticas dos professores com a construção do 
currículo. Ela também atribui esses sentidos potencializados nesse dialogismo com os professores, pois isso é um reflexo de sua própria constituição e como ela vê sua importância e a de seus pares dentro da Secretaria: "Isso eu acho que acontece em todos os municípios. São professores da rede que são convidados a trabalhar na Secretaria. Então nós sempre estamos muito ligados ao nosso fazer docente. Eu estou na secretaria, mas eu sou professora" (COSMO).

Um outro papel que a pesquisadora possui dentro do município é o de formadora. Ela descreve como se dá essa atividade:

\begin{abstract}
$\mathrm{E}$ as minhas experiências hoje elas estão relacionadas a essa formação, a formação de professores, e eu sou professor formadora e assessora formadora. Por quê? Além de eu trabalhar com a formação, dar a formação, fazer formação junto com a minha equipe de trabalho, com os meus colegas de trabalho, eu também sou assessora. Eu vou às escolas para saber como que está sendo implementado esse currículo, como essas teorias que discutimos, essas experiências que estão sistematizadas no documento curricular estão acontecendo na prática, porque agora eu tenho que saber e ter esse feedback do que foi pensado no coletivo, se também realmente está acontecendo na prática, então nós realizamos também esse papel de assessoria, formação, de estar indo no lócus das escolas para saber como que está sendo implementado nosso documento curricular. E aí, aqui, nos dividimos por região, por escolas, para que nenhuma escola fique sem ser ouvida, sem ter a visita de nosso assessor, profissional da Secretaria (COSMO).
\end{abstract}

Assim, uma das funções da equipe da Secretaria é o acompanhamento de como tudo que se é discutido se dá na prática, no chão da escola. Essa preocupação é muito importante, para que se evitem mecanismos que distanciam o discurso da prática que se encontra na escola, mantendo o constante dialogismo das relações entre professores e Secretaria e se aproximando do que acontece na escola, ouvindo constantemente seus profissionais.

Essa discussão acabou por fazê-la se lembrar dos planos de trabalho que as escolas desenvolvem nesses modos de visibilizar a interface. Novamente vamos nos envolvendo nas temáticas que a escola assume discutir. A educação especial aparece em meio às outras discussões que são sinalizadas: 
É um dos planos de trabalho que as escolas vem desenvolvendo. No ano passado nos definimos os principais norteadores do nosso trabalho docente dentro da educação do campo. Que são Educação socioambiental e sustentabilidade, inclusão, diversidade, relações de gênero, orientação sexual, relação étnico-raciais, educação especial e direitos humanos. Então é isso que está sendo discutido dentro da educação do campo em todas as escolas do município (COSMO),

Ouvimos da autora o quantitativo de escolas multisseriadas no município, uma preocupação comum entre todos os que discutem a educação do campo, que se refere à política de precarização que vem vivida nas escolas do campo e ao fechamento dessas escolas. Assim ela nos diz:

A nossa realidade municipal também se diferencia um pouco das realidades urbanas, porque nós temos 23 escolas uni e pluridocentes, ou seja, têm escolas ainda que só têm um professor e a servente. Têm escolas que têm mais de um professor, dois professores, ou seja, escolas que trabalham do primeiro ao quinto ano em uma única série. Temos ainda, e é bom que tenhamos, porque existiu uma politica de nuclear essas escolas, de fechar essas escolas do campo e levar para as EMEFs mais próximas e aqui, no municipio, nós já discutimos uma política de resistência e de contravenção a isso, porque nós não queremos que essas escolas do campo, essas uni pluri mais especificamente sejam fechadas [...] (COSMO).

Pensando mais especificamente na história da educação especial no município, a autora analisa as tensões que emergiram pela força das instituições especializadas Apae e Pestalozzi e pela resistência dos professores em aceitar a inclusão dos alunos público-alvo da educação especial nas salas de aula:

Nós temos, sim, desafios, a partir do momento em que essas crianças passaram a ser matriculadas nas escolas regulares, aqui do município, nosso município, porque nós temos uma Apae em Domingos Martins e temos uma Pestalozzi em Marechal Floriano. Então esse movimento que existia em matricular essas crianças nas escolas especializadas é muito forte. Ele foi sendo desconstruído a partir da política pública do município. Nós fomos destacando e fortalecendo isso que essas crianças possam ter acesso à escola regular e permanecer na escola regular. Aî, com isso, foi um grande desafio aqui, no municipio, porque muitos professores às vezes eram resistentes. Isso, há anos passados. Resistentes, insistindo para que a criança permanecesse na escola especializada, mas foi um movimento que foi se desconstruindo (COSMO).

Assim, com a gradual mudança de como a educação especial foi sendo trabalhada no municipio, estratégias de formação para os profissionais da educação foram sendo pensadas, para que pudessem abranger todos os 
professores, pois pela distância ou pela dificuldade de reuni-los em uma formação com todos juntos a forma de aproximação dessa formação foi adquirindo uma maneira diferenciada de trabalho:

Como não dá para fazer com todos os professores, com os 500 professores da rede nesse momento; é feito com o professor de Atendimento Educacional Especializado, com o pedagogo e com o diretor, porque eles estão intimamente ligados também nesse processo de ensino e aprendizagem dessa criança especial. E o professor pedagogo e o diretor fazem interlocução com o professor da rede regular (COSMO).

Evidencia outras estratégias para que a formação chegue até os professores de regiões mais distantes da sede.

O nosso deslocamento da Secretaria é muito mais fácil para irmos à região do que o professor vir para a sede. Então esse movimento a gente faz continuamente, a gente regionaliza para potencializar os encontros e otimizar a questão da logística também, porque, se um professor que sai... Vou te dar um exemplo de um local... De Tijuco Preto, para vir aqui, ele tem que sair muito cedo, cinco horas da manhã para estar aqui às oito. Agora, quando eu regionalizo eu tento concentrar mais próximo da casa dele ou da escola em que ele trabalha para que ele não saia tão cedo e, às vezes, não o desmotive a participar da formação (COMOS);

As estratégias de alcançar os professores em sua formação continuada têm um contexto bem diferenciado no município. Quando é pensada a educação especial, eles partem do diretor, pedagogo e professor de Educação Especializado e com eles fica a responsabilidade de fomentar o que foi considerado na formação para os professores de sala regular. Isso envolve diferentes profissionais dentro da escola, não deixando apenas para o professor especialista, como figura central da escolarização do aluno, e distante do professor. Também há as formações que conseguem pensar de forma regional pela extensão do município, permitindo que não precisem ser feitos grandes deslocamentos, desmotivando a formação.

Finalizando sua narrativa, é colocado que o documento curricular desenvolvido permitiu que se pensasse em uma estratégia para disparar uma politica que pudesse ser duradoura, distanciando as tensões já colocadas por outras autoras, ou seja, uma politica centrada na figura de um profissional e, com a saída do profissional, tudo que foi construído terminava com tal saída: 
E aí a produção do nosso documento curricular calhou em a gente pensar em uma política pública também de Estado e não de governo porque municipios do interior têm muito isso. Entra prefeito e sai prefeito, muda a política de trabalho e aí, com a implementação do nosso documento curricular, vai ser constituida uma comissão de acompanhamento também da implementação e continuidade desse documento. Foi um documento construído com todos, para que não entre prefeito e saia prefeito e desconstrua essa produção que levou três anos para ficar pronta. Então é uma potência para isso (COMOS).

\section{Considerações}

Este estudo possibilitou entender que a invisibilização e os silenciamentos se dão por mecanismos que atuam a partir de uma dada realidade hegemônica de mundo e que permite que a desigualdade e a exclusão seja forte o suficiente a ponto de a Educação Especial e a Educação do Campo não se derem conta de que uma está contida na outra.

A partir deste estudo, apontamos para pistas de superação de dicotomias. Foi possível fazer constatar que, dentro de realidades que invisibilizam também há visibilizações, só não foram percebidas. Na medida em que o pesquisador é "questionado" em sua própria realidade, começamos a perceber as existências. A produção de "não-existência" problematizada permite identificar movimentos de resistência. Precisamos assumir um olhar sensivel para essas realidades que compuseram o estudo em tela, pois, ditas ou não, elas continuaram presentes.

Assim sendo, quando trouxemos para esse artigo o caso de Cosmo, como pesquisadora, percebemos, dentro de seu contexto dos dados apontados por ela, que a interface entre a educação especial e educação do campo se encontra presente dentro da realidade do municipio de Domingos Martins, onde atua como profissional. As pistas, os “embriões" (SANTOS, 2006) de possibilidades existentes nesse municipio foram evidenciados. Assim sendo, esse artigo buscou dar possibilidade de mostrar existências e inexistências produzidas pelos modos como a Interface vem sendo construída em diferentes territórios. Buscamos tornar visível a possibilidade de o conhecimento socialmente sustentável no campo, incluir os saberes-fazeres da educação especial em uma perspectiva inclusiva. 
Com Cosmo, pudemos nos apropriar de sua experiência na Secretaria de Domingos Martins e foi possivel vislumbrar a possibilidade de se pensar a interface entre a educação especial e a educação do campo. Entendemos que essa interface só foi potencializada pela política que o município assumiu de pensar prioritariamente todas as escolas como sendo escolas do campo. Cabe destacar que, mesmo o campo sendo forte nas outras regiões, ele ainda se encontra em condição de desigualdade, se comparado com o urbano, pois percebemos a precarização do campo nos estudos que colocam a modalidade da educação do campo em tela.

Assim sendo, a pesquisadora nos ensina sobre a potencialidade do constante diálogo com os professores, suas demandas e desafios encontrados em suas realidades locais. Esse dialogismo produz um trabalho coletivo que possibilita atuar em diferentes frentes para a realidade educacional do municipio, focando também as questões da educação especial.

Em síntese, acreditamos que precisamos ouvir mais os pesquisadores, não apenas narrando sobre o que produziram, mas sobre elementos que perpassam trajetórias de vida do ser pesquisador, do ser profissional. Perceber seus envolvimentos com suas áreas de estudo, suas motivações, enfim, ouvilos, pois eles possuem algo a nos contar que vai para além do que foi pesquisado e certos silenciamentos presentes apenas não foram ouvidos "ainda" porque o outro não se dispôs a ouvi-los.

Finalizamos chamando a atenção para a importância de se produzir mais pesquisas sobre a interface entre a Educação Especial e a Educação do Campo, visto que, em nossa pesquisa, encontramos pistas de total invisibilização, até daquelas que se constituem na interface se materializando como no caso apresentado nesse artigo. Precisamos evitar outros períodos de silenciamentos.

\section{Referencias}

ALMEIDA, M. L. Uma análise da produção acadêmica sobre os usos da pesquisa-ação em processos de inclusão escolar: entre o agir comunicativo e o agir estratégico. 2010. Tese, (Doutorado em Educação) - 
Programa de Pós-Graduação em Educação, Universidade Federal do Espirito Santo, Vitória, 2010.

ANJOS, C. F. Realidades em contato: construindo uma interface entre a educação especial e a educação do campo. Dissertação (Mestrado em Educação) Programa de Pós Graduação em Educação, Universidade Federal do Espirito Santo, Vitória, 2016.

ANJOS, C. F. Indicadores de matriculas sobre a interface entra educação especial e educação do campo: o que os dados nos revelam? In Anais do IV Colóquio Educação Especial e Pesquisa: história, política, formação e práticas pedagógicas 4. ed. - Vitória, ES, 2017.

CAIADO, K. R. M. Educação Especial no campo: uma interface a ser construida. In: I Seminário de Políticas Públicas de Inclusão Escolar no Rio Grande do Sul, 2010, Porto Alegre, RS. Anais do I Seminário de Politicas Públicas de Inclusão Escolar no Rio Grande do Sul. Marília, SP: ABPEE - ISSN: 2178-4663, 2010.

COSMO, M. Ser Pomerana: histórias que desvela as memórias, a experiência e os sentidos de ser professor. 2014. Dissertação (Mestrado em Educação) -Universidade federal do Espirito Santo, Programa de Pós Graduação em Educação, Vitória, 2014.

CUNHA, M. I da. Conta-me agora! as narrativas como alternativas pedagógicas na pesquisa e no ensino. Rev. Fac. Educ.[on-line], v. 23, n.1 - 2, 1997.

GUIMARÂES, A. S. Critica da razão excludente: desvelando novas racionalidades a partir das pesquisas em educação especial numa perspectiva inclusiva -2014 . Tese, (Doutorado em Educação) - Programa de Pós-Graduação Em Educação, Universidade Federal do Espírito Santo, Vitória, 2014,

JESUS, D. M; ANJOS, C. BERGAMI, C. Z. Educação no Campo e Educação Especial: o que pensam os gestores de Educação Especial. In: Encontro De Pesquisa Em Educação Da Região Sudeste - Pós-Graduação Em Educação Na Região Sudeste Em Suas Múltiplas Dimensões, Rio de Janeiro 2011.

LABOV, W. The transformation of experience in narrative sintax. In:

(Ed.). Language in the Inner City. Philadelphia: University of Pennsylvania, 1972. p. 352-96.

NOZU. W. C. S. Educação Especial e Educação do Campo: entre porteiras marginais e fronteiras culturais Tese (Doutorado em Educação) Faculdade de Educação, Universidade Federal da Grande Dourados, Dourados, 2017.

SANTOS, B. S. Uma cartografia simbólica das ciências sociais: prolegomenos a uma concepção pós-moderna do direito. Revista Critica de Ciências Sociais. mar., 1988. 
SANTOS. Para uma sociologia das ausências e uma sociologia das emergências. In: - (Org.). Conhecimento prudente para uma vida decente: um discurso sobre as ciências revisitada. 2. ed. São Paulo: Cortez, 2006. p. $777-815$

Renovar a teoria critica e reinventar a emancipação social São Paulo: Boitempo, 2007.

Para além do pensamento abissal: das linhas globais a uma ecologia dos saberes. In: SANTOS, B. S; MENESES, M. P. (Org.). Epistemologias do Sul. São Paulo: Cortez, 2010.

RABELO, A. O. Reflexões sobre a investigação narrativa na educação, Educ. Soc., Campinas, v. 32, p. 171-188, jan./mar. 2011.

SEEMANN, Jörn. Cartografia e cultura: abordagens para a geografia cultural. In: Zeny Rosendahl; Roberto Lobato Correa. (Org.). Temas e caminhos da geografia cultural. Rio de Janeiro: Editora de UERJ, 2010.

SKLIAR, Carlos. (Org). Derrida \& a Educação. Belo Horizonte: Autêntica Editora, 2005. 